\title{
STUDI KASUS STABILITAS STRUKTUR TANAH LEMPUNG PADA JALAN TOTOK KEROT KEDIRI MENGGUNAKAN LIMBAH KERTAS
}

\author{
${ }^{1}$ Agata Iwan Candra, ${ }^{2}$ Sulik Anam, ${ }^{3}$ Zendy Bima Mahardana, ${ }^{4}$ Andri Dwi Cahyono \\ 1,2,3,4 Fakultas Teknik Universitas Kadiri
}

e-mail: iwan_candra@unik-kediri.ac.id,sulik_anam@unik-kediri.ac.id, zmahardana@unik-kediri.ac.id, adcahyono@unik-kediri.ac.id

\begin{abstract}
The stability of the soil structure is something that needs to be considered in development. Increasing soil structure improvement can be done through various efforts using added materials or compaction processes. This study aims to improve the clay soil on the kerot kediri road using paper waste. The research was conducted experimentally by making samples in the laboratory. The land used is from the Totok Kerot road, Kediri, which has damaged the road surface due to land loans. Waste paper was added at $0 \% 7.5 \%, 10 \%, 15 \%$, and $20 \%$ of the weight of the test object. Waste paper is used with pulp after it is dried and pulverized to a certain gradation. The tests carried out include the Consistency Limit (Atterberg Limit) and Soil Compaction (Proctor) tests. The results showed that the addition of waste paper affects the original properties of the soil. The addition of paper moisture content decreases the Plastic Index value and increases the dry volume of the soil. The addition of waste paper content also increases the volume of dry soil water but decreases after reaching the optimum point, namely at $10 \%$ paper waste content and $9.96 \%$ water content with a dry volume weight value of $1.97 \mathrm{gr} / \mathrm{cm} 3$. The greater the dry volume of soil, the dry density indicates that the soil is getting higher. So that by knowing these results, it can be used as a reference in the process of repairing and backfilling the soil on the Totok Kerot Kediri road.
\end{abstract}

Keywords: Clay Soil, Paper Waste, Soil, Soil Stability

\begin{abstract}
ABSTRAK
Stabilitas struktur tanah menjadi hal yang perlu diperhatikan dalam pembangunan konstruksi. Peningkatan stabilitas struktur tanah dapat dilakukan melalui berbagai upaya seperti pengguunaan bahan tambah ataupun proses pemadatan. Penelitian ini bertujuan untuk meningkatkan stabilitas tanah lempung pada jalan totok kerot kediri menggunakan limbah kertas. Penelitian dilakukan secara eksperimental degan pembuatan sampel di Laboratorium. Tanah yang digunakan berasal dari jalan Totok Kerot Kediri yang mengalami kerusakan permukaan jalan akibat efek lendutan tanah. Limbah kertas yang ditambahkan sebesar 0\% 7.5\%, 10\%, 15\% dan 20\% dari berat benda uji. Limbah kertas diproses dengan menjadikannya bubur kertas yang setelahnya dikeringkan dan dihaluskan dengan gradasi tertentu. Pengujian yang dilakukan meliputi uji Batas konsistensi (Atterberg Limit) dan Pemadatan Tanah (Proctor). Hasil penelitian menunjukkan bahwa penambahan limbah kertas mempengaruhi sifat asli tanah. Penambahan kadar limbah kertas menurunkan nilai Indeks Plastis serta meningkatkan berat volume kering tanah. penambahan kadar limbah kertas juga meningkatkan berat volume kering tanah namun mengalami penurunan setelah dicapainya titik optimum yaitu pada kadar limbah kertas 10\% dan kadar air 9,96\% dengan niali berat volume kering sebesar $1,97 \mathrm{gr} / \mathrm{cm}^{3}$. Semakin besar berat volume kering suatu tanah menunjukkan kepadatan kering tanah yang menunjukkan bahwa stabilitas tanah semakin tinggi. Sehingga dengan diketahuinya hasil tersebut, dapat digunakan sebagai acuan dalam proses perbaikan serta pengurukan tanah pada jalan Totok Kerot Kediri.
\end{abstract}

Kata Kunci: Limbah Kertas, Tanah, Tanah Lempung, Stabilitas Tanah 


\section{PENDAHULUAN}

Tanah merupakan suatu material yang terdiri dari berbagai unsur agregat atau butiran mineral padat. Tanah menjadi komponen terpenting dalam konstruksi bangunan. Fungsi utama tanah yaitu sebagai pendukung pondasi serta perletakan bangunan[1][2]. Tanah terdiri dari berbagai ukuran butiran beragam yang terbentuk karena pelapukan alami batuan[3]. Ukuran butiran tersebut dapat diklasifikasikan menjadi empat golongan yaitu kerikil (gravel), pasir (sand), lanau (silt), dan lempung (clay). Berbagai jenis tanah tersebut memiliki karakteristik yang berbeda.

Tanah lempung merupakan salah satu jenis tanak lunak dengan karakteristik tanah berbutir halus [4]. Tanah tersebut memiliki sifat kembang susut dimana ketika terkena air akan mengembang sesuai jumlah air yang terserap, namun ketika dalam keadaan kering akan menyusut seperti dimensi semula dengan pemadatan yang tidak terarah [5]. Konsistensi tanah berlempung kurang mendukung terhadap keamanan bangunan yang ditopangnya. Tanah dengan kadar lempung tinggi memiliki daya dukung tanah yang rendah sehingga perlu diperkuat dengan proses stabilisasi tanah atau perbaikan tanah [7][6]. Komponen struktur tanah yang terdapat pada jalan Totok Kerot Kediri berupa tanah lempung. Struktur tanah tersebut menjadikan permukaan tanah menjadi bergelombang, terlebih ketika permukaan tanah tersebut digunakan sebagai jalan perlintasan kendaraan berat. Sehingga perlu dilakukannya stabilisasi tanah.

Stabilisasi tanah dilakukan untuk memperbaiki sifat asli tanah serta meningkatkan kualitas tanah sehingga menunjang keamaan suatu bangunaan [8]. Stablisasi tanah dilakukan dengan menambahkan bahan-bahan terntu pada susunan tanah asli [10]. Penambahan bahan tersebut diharapkan mampu mengubah atau memperbaiki sifat dasar tanah lempung [11]. Selain penggunaan bahan tambah, kualitas tanah juga dapat ditingkatkan melalui proses pengurukan serta pemadatan yang tepat. Dengan pemadatan, maka butir-butir tanah akan merapat sehingga volume tanah dan volume pori berkurang namun volume butir tidak berubah. Tanah yang stabil akan meningkatkan kekuatan geser tanah, daya dukung dan permeabilitas tanah [9].

Beberapa penelitian mengenai penggunaan bahan tambah untuk perbaikan tanah telah banyak dikembangkan. Penggunaan bahan tambah berbahan dasar limbah seperti limbah plastik, kapur, limbah gypsum [12][13][14], menunjukkan bahwa bahan-bahan tersebut mampu memperbaiki karakteristih tanah secara signifikan. Namun, belum banyak penelitian yang mengulas mengenai penggunaan limbah kertas sebagai stabilisati tanah. Limbah kertas sendiri masuk kedalam ketegori limbah padat domestik yang penguraiannya lumayan sulit, sifatnya padat namun lolos air sehingga terbilang cukup bagus[15]. 
Penelitian ini bertujuan untuk meningkatkan stabilitas tanah lempung pada jalan totok kerot kediri dengan penggunaan limbah kertas. Limbah kertas yang ditambahkan sebesar $0 \%, 7.5 \%, 10 \%, 15 \%$ dan $20 \%$ dari berat benda uji. Sehingga dengan diketahuinya nilai stabilitas dengan penggunaan limbah kertas, maka dapat digunakan sebagai perbaikan kondisi tanah pada jalan totok kerot.

\section{METODE PENELITIAN}

Penelitian dilakukan dengan metode eksperimental dengan pembuatan sampel penelitian di Laboratorium Teknik Sipil Universitas Kadiri. Sampel yang digunakan berupa tanah yang berasal dari jalan Totok Kerot Kediri dengan karakteristik tanah lempung. Perbaikan tanah lempung dilakukan dengan menambahkan limbah kertas. Limbah kertas yang ditambahkan sebesar 0\%, 7.5\%, 10\%, 15\% dan 20\% dari berat benda uji. Pengujian yang dilakukan meliputi uji konsistensi tanah serta uji pemadatan tanah. Dari pengujian tersebut akan diketahui satbilitas struktur tanah dengan penggunaan limbah kertas.

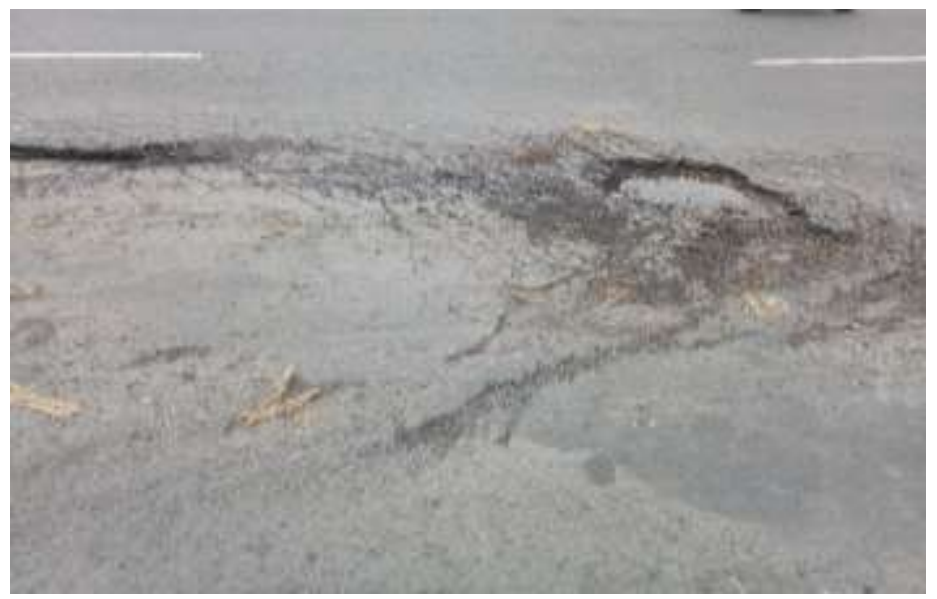

Gambar 1. Kondisi Jalan Totok Kerot Kediri

Sumber: Dokumentasi penelitian

\subsection{Material}

Material yang digunakan meliputi tanah lempung, air serta limbah kertas dengan uraian sebagai berikut:

1) Tanah Lempung

Tanah yang digunakan berupa tanah asli yang diperkirakan berjenis lempung yang berasal dari jalan Totok Kerot Kediri. Tanah diambil dengan menggunakan cangkul pada kedalaman kurang lebih 50-100 cm (diperkirakan tidak mengandung humus). Dilakukan pengeringan pada tanah asli tersebut menggunakan oven [16]. Tanah lempung kering yang digunakan sebagai sampel merupakan tanah dengan gradasi butiran lolos pada ayakan 40 . 


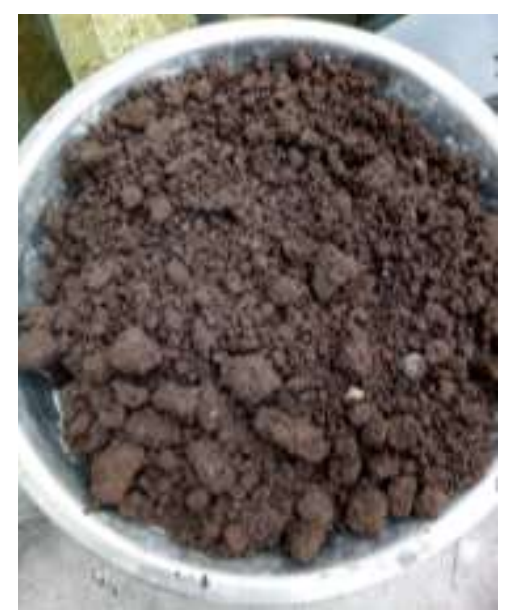

Gambar 2. Tanah lempung

Sumber: Dokumentasi penelitian

2) Air

Air digunakan untuk membantu proses pelarutan reaksi tanah lempung dan limbah kertas pada proses mixing. Air yang digunakan berupa air PDAM Universitas Kadiri dengan Ph 7.

3) Limbah Kertas

Limbah kertas berupa partikulat (padat) zat kimia terutama yang mengandung $\mathrm{Ca}$ dapat dijadikan bahan pencampur pada stabilisasi tanah. Pada limbah kertas yang terdapat unsur $\mathrm{Ca}$, jika bereaksi dengan air dan lempung akan menjadi $\mathrm{Ca}++$ sehingga dapat mengikat partikel- partikel lempung yang mempunyai ion-ion negative pada permukaannya. Bahan pendukung yang digunakan sebagai stabilisator tanah dalam penelitian berikut adalah limbah padat kertas berwujud sebagai kertas Hvs, folio, buku tulis dan koran bekas tak terpakai. Limbah kertas yang awalnya berupa lembaran diproses menjadi bubur kertas, lalu dilakukan pengeringan serta penghalusan dengan gradasi tertentu[15].

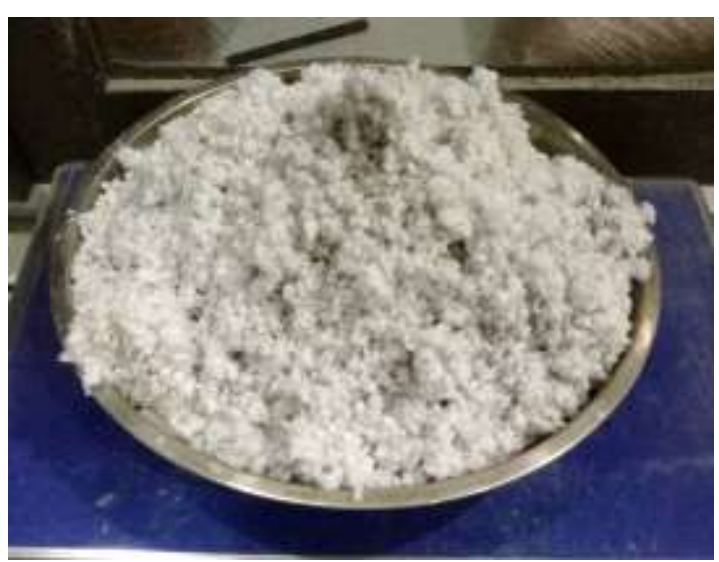

Gambar 3. Limbah kertas

Sumber: Dokumentasi penelitian

\subsection{Pengujian Sampel}

Pengujian yang dilakukan meliputi pengujian konsistensi tanah serta pemadatan tanah dengan uraian sebagai berikut: 
1) Uji Konsistensi

Pengujian batas konsistensi (Atterberg limits) [17], dilakukan untuk mengetahui batas cair serta batas plastis tanah[18][19]. Dari hasil tersebut, diketahui indeks plastisitas suatu tanah. Indeks plastisitas suatu tanah dapat menentukan jenis tanah dan kohesinya.

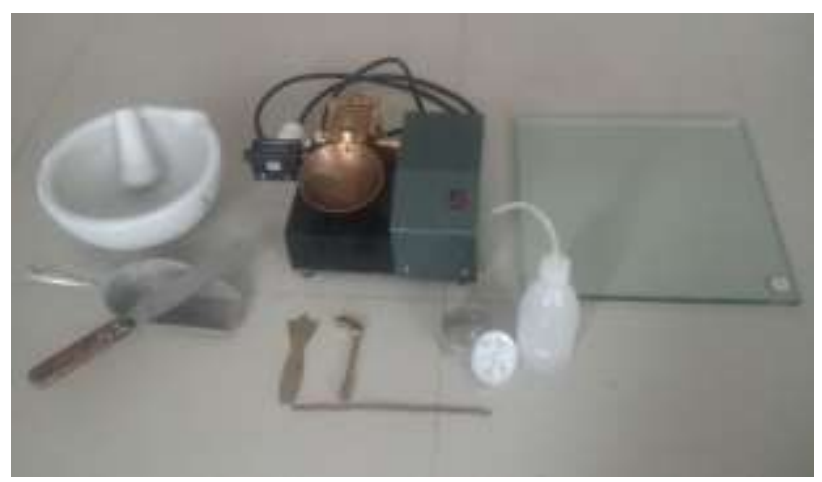

Gambar 4. Alat Uji Konsistensi Tanah

Sumber: Dokumentasi penelitian

\section{a. Pengujian Batas Cair (Liquit Limit)}

Uji liquid limit dilakukan dengan menggunakan alat Cassagrande. Pengujian dilakukan untuk mengetahui beberapa besar kadar air suatu komposisi penyusun struktur tanah pada benda uji saat keadaan batas cair. Rumus yang digunakan untuk menentukan kadar air diuraikan sebagai berikut :

$\mathrm{WW}=\mathrm{W}-\mathrm{Ws}$

$\mathrm{Wc}=(\mathrm{Ww} / \mathrm{Ws}) \times 100 \%$

keterangan

$\mathrm{W}=$ Berat tanah basah

Ws $=$ Berat tanah kering

$\mathrm{Ww}=$ Berat air

Wc $=$ Kadar air

b. Uji Plastic Limit

Batas plastis merupakan batas terendah dari tingkat keplastisan suatu tanah. Pengujian plastic limit dimaksudkan untuk mengetahui kadar air minimum dimana sifat suatu jenis tanah berubah dari keadaan cair menjadi plastis. Untuk rumus perhitungannya :

$P L=\frac{\text { Penjumlahan Wc setiap percobaan }}{\text { jumlah Percobaan }}$

$\mathrm{Ww}=\mathrm{W}-\mathrm{Ws}$

$\mathrm{Wc}=\mathrm{Ww}-\mathrm{Ws}$

keterangan

PL $=$ Plastis Limit 
$\mathrm{W}=$ Berat tanah basah

$\mathrm{Ws}=$ Berat tanah kering

$\mathrm{Ww}=$ Berat air

Wc $=$ Kadar air

2) Uji Pemadatan Tanah (Proctor)

Pengujian Pemadatan Tanah (Proctor) dimaksudkan untuk mengetahui nilai kepadatan tanah maksimum setelah dilakukan tumbukan pada struktur benda uji. Tumbukan dilakukan sebanyak 25 kali tumbukan. Dari pengujian pemadatan, akan diketahui berat volume kering pada serta kadar air tanah. Perubahan volume tanah dapat menyebabkan kerusakan yang sangat signifikan pada struktur ringan seperti retakan pada dinding gedung [20]. Perhitungan hasil uji pemadatan dapat dihitung menggunakan rumus berikut:

$\gamma \mathrm{d}=\mathrm{Ws} / \mathrm{V}$

$\gamma \mathrm{sat}=\mathrm{W} / \mathrm{V}$

$\mathrm{V}=\pi \times \mathrm{r}^{2} \times \mathrm{t}$

$\mathrm{W} w=\mathrm{W}-\mathrm{Ws}$

$\mathrm{Wc}=\mathrm{Ww} / \mathrm{Ws} \times 100 \%$

keterangan

$\gamma \mathrm{d}=$ Berat volume kering

$\gamma$ sat $=$ Berat Volume Basah

$\mathrm{V}=$ Volume isi cetakan

$\mathrm{W}=$ Berat tanah basah

$\mathrm{Ws}=$ Berat tanah kering

$\mathrm{WW}=$ Berat air

$\mathrm{Wc}=$ Kadar air

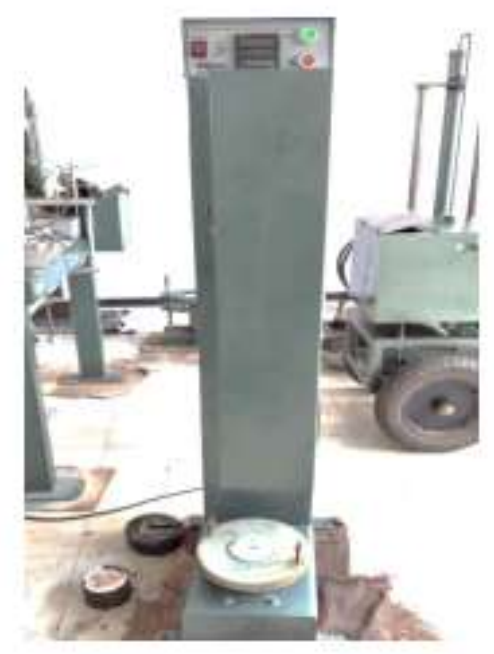

Gambar 5. Alat Uji Proctor

Sumber: Dokumentasi penelitian 


\section{HASIL DAN PEMBAHASAN}

\subsection{Uji Konsistensi}

Pengujian konsistensi tanah meliputi pengujian batas cair dan pengujian batas plastis. Kedua pengujian ini dilakukan pada tanah lempung asli serta pada tanah dengan penambahan limbah kertas. Hasil pengujian diuraikan sebagai berikut:

Tabel 1. Batas-batas konsistensi tanah

\begin{tabular}{|c|c|c|c|}
\hline $\begin{array}{c}\text { Limbah Kertas } \\
(\%)\end{array}$ & $\begin{array}{c}\text { Liquid Limit } \\
(\%)\end{array}$ & $\begin{array}{c}\text { Plastic Limit } \\
(\%)\end{array}$ & $\begin{array}{c}\text { Index Plastic } \\
(\%)\end{array}$ \\
\hline 0 & 57 & 24,44 & 32,56 \\
\hline 7,5 & 51 & 29,22 & 21,78 \\
\hline 10 & 49 & 29,75 & 19,25 \\
\hline 15 & 42 & 29,92 & 12,08 \\
\hline 20 & 43 & 31,64 & 11,36 \\
\hline
\end{tabular}

\section{Sumber: Hasil Penelitian}

Dari tabel diatas dapat digambarkan dalam bentuk grafik sebagai berkut:

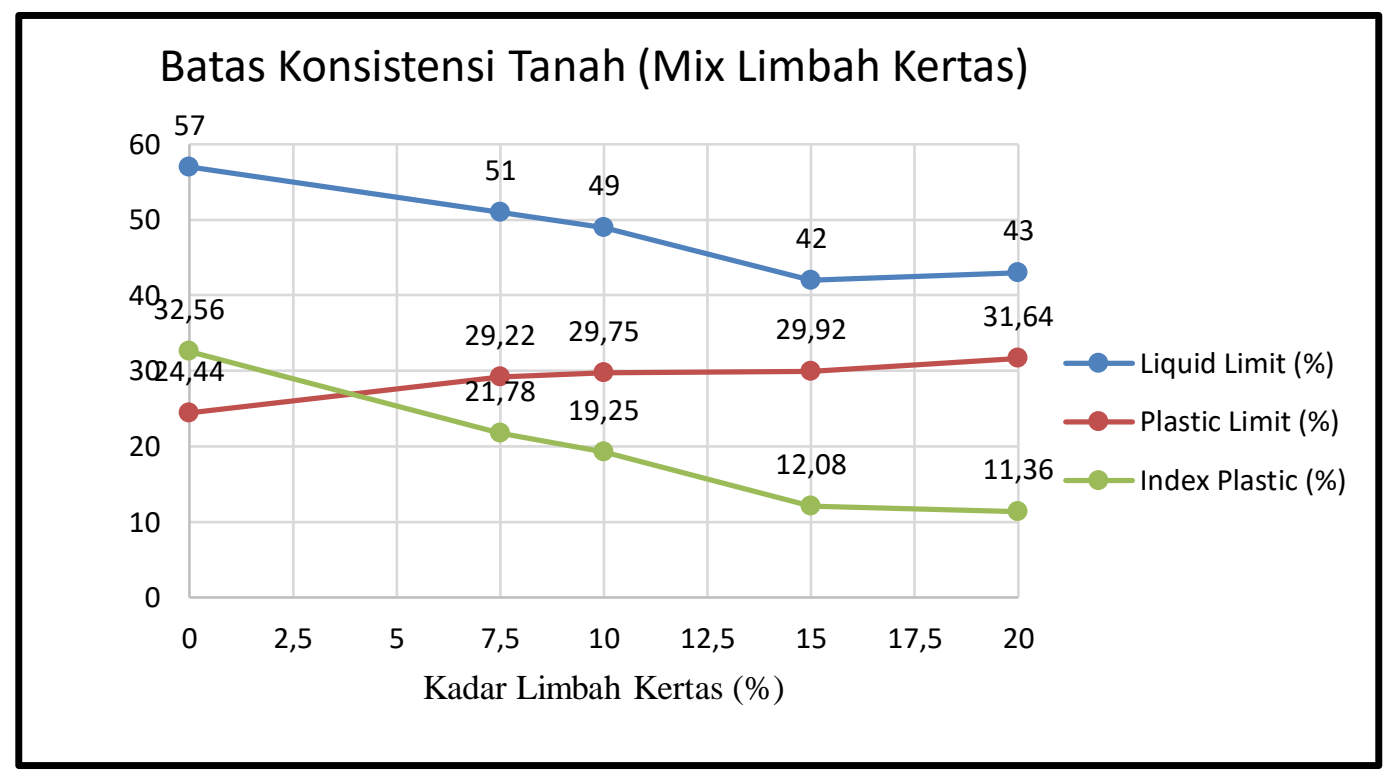

Gambar 6. Grafik Hasil Uji Batas Konsistensi pada benda uji

Sumber: Hasil Penelitian

Pada pengujian batas konsistensi struktur tanah diketahui batas cair tertinggi diperoleh pada tanah asli dengan prosentase sebesar 57\% dengan nilai batas plastis, Nilai Plastic Limit sebesar 24,44\% dan nilai index plastic sebesar 32,56 \%. Pada struktur benda uji tanah yang telah ditambahkan limbah kertas hingga sebesar 20\% mengalami penurunan nilai Liquid Limit hingga menjadi 43\%, dengan demikian menunjukkan bahwa penambahan 
limbah kertas pada struktur tanah dapat meminimalisir penyerapan air, sehingga selisih aktivitas kembang-susut struktur tanah akibat menyerap air menjadi lebih stabil. Nilai angka uji Plastic Limit meningkat menjadi 31,64\%, hal tersebut menunjukkan bahwa benda uji mix tanah lempung yang ditambah dengan limbah kertas sebesar $20 \%$ dari berat kering benda uji memerlukan air lebih banyak untuk mencapai keadaan plastis. Pada hasil akhir perhitungan menunjukkan nilai Index Plastic pada benda uji mix tanah dengan 20\% limbah kertas menurun hingga menjadi 11,36\%. Hal tersebut menyimpulkan bahwa indeks plastis benda uji mix tanah dengan $20 \%$ limbah kertas jauh lebih kecil jika dibanding dengan struktur tanah asli.

\subsection{Uji Pemadatan (Proctor)}

Pengujian Compaction test atau pemadatan tanah dilakukan pada benda uji tanah lempung berbutir halus dengan tingkat lolos ayakan No.40 dan penambahan limbah kertas $0 \%, 7.5 \%, 10 \%, 15 \%$ dan $20 \%$ dari berat benda uji. Dari hasil pengujian Compaction test yang telah dilaksanakan dapat diperoleh hasil dalam tabel dan grafik sebagai berikut:

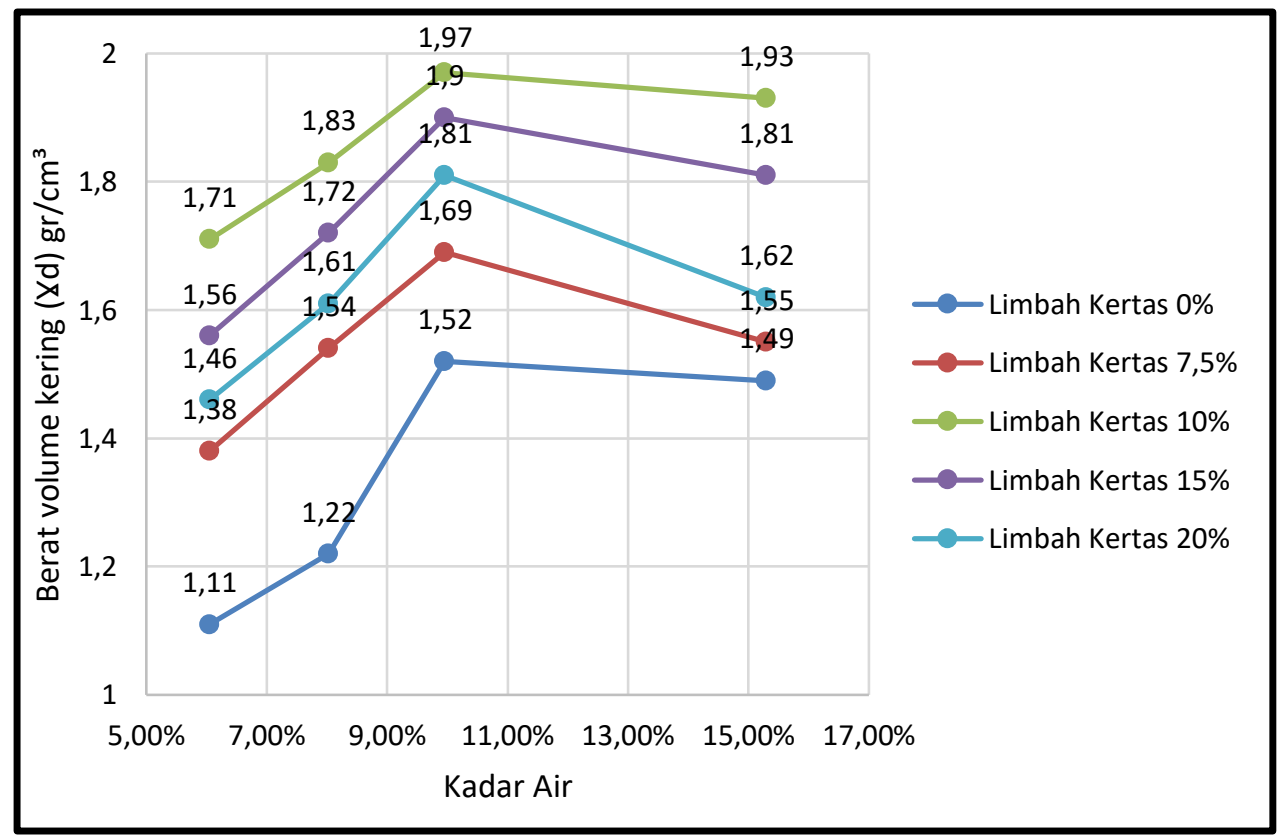

Gambar 7. Hasil uji pemadatan

Sumber: Hasil Penelitian 


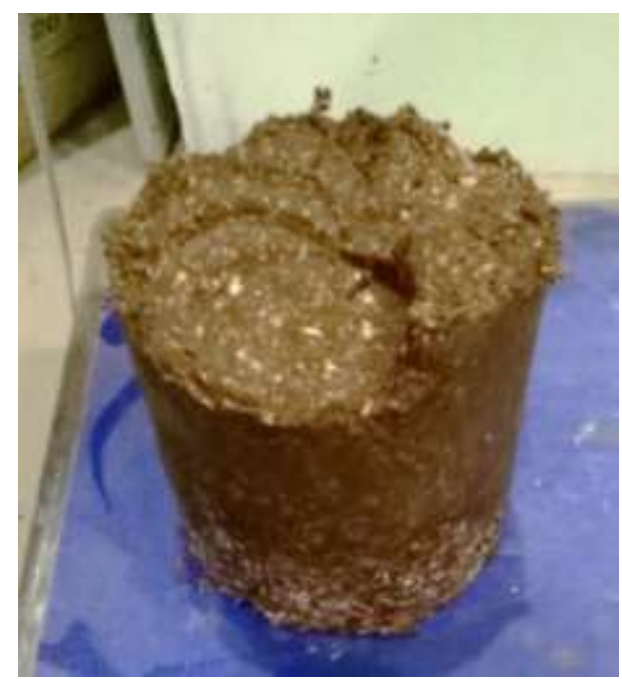

Gambar 8. Sampel Uji Pemadatan Tanah

Sumber: Dokumentasi Penelitian

Dari hasil pengujian pemadatan yang disajikan pada gambar grafik 5 diketahui bahwa berat volume kering meningkat seiring ditingkatkannya kadar limbah kertas, namun mengalami penurunan setelah dicapainya titik optimum. Berat volume kering tertinggi diperoleh pada penambahan limbah kertas sebanyak 10\% dengan nilai sebesar 1,97 $\mathrm{gr} / \mathrm{cm}^{3}$ dengan kadar air optimum sebesar $9,96 \%$

\section{KESIMPULAN DAN SARAN}

\subsection{Kesimpulan}

Penambahan limbah kertas mempengaruhi sifat asli tanah. Penambahan kadar limbah kertas menurunkan nilai Indeks Plastis. Semakin kecil indeks plastis yang diperoleh maka semakin besar kemungkinan tanah dalam kondisi plastis. Hal tersebut menunjukkan bahwa nilai daya dukung tanah semakin besar. Selain itu, penambahan kadar limbah kertas juga meningkatkan berat volume kering tanah namun mengalami penurunan setelah dicapainya titik optimum yaitu pada kadar limbah kertas $10 \%$ dan kadar air 9,96\%. Semakin besar berat volume kering suatu tanah menunjukkan kepadatan kering tanah. Sehingga stabilitas tanah semakin tinggi. Sehingga dengan diketahuinya hasil tersebut, dapat digunakan sebagai acuan dalam proses perbaikan serta pengurukan tanah pada jalan Totok Kerot Kediri.

\subsection{Saran}

Pada Penelitian berikut, peneliti mengasumsikan penambahan limbah kertas maksimal adalah $20 \%$ dari berat kering benda uji, hal tersebut ditujukan karena ingin tetap mempertahankan zat pengikat yang dalam hal ini hanya terdapat pada struktur tanah. 


\section{DAFTAR PUSTAKA}

[1] W. A. Prawesthi and L. P. Santosa, "Stabilization of the Shear Strength of Clay Soil with Limestone Powder," no. C, pp. 549-556, 2017.

[2] J. Widjajakusuma and H. Winata, "Influence of Rice Husk Ash and Clay in Stabilization of Silty Soils Using Cement," MATEC Web Conf., vol. 138, 2017.

[3] B. V. Venkatarama Reddy and M. S. Latha, "Retrieving clay minerals from stabilised soil compacts," Appl. Clay Sci., vol. 101, pp. 362-368, 2014.

[4] M. R. Abdurrozak et al., "STABILISASI TANAH LEMPUNG DENGAN BAHAN TAMBAH ABU SEKAM," Teknisia, vol. XXII, no. 2, pp. 416-424, 2017.

[5] V. A. Upa and N. Hakim, "Analisis Kekuatan dan Stabilitas Tanah Lempung Organik Artifisial Untuk Perencanaan Jalan dengan Beban Lalu Lintas Tinggi," J. Apl. Tek. Sipil, vol. 17, no. 2, p. 37, 2019.

[6] S. Pourakbar, A. Asadi, B. B. K. Huat, and M. H. Fasihnikoutalab, "Stabilization of clayey soil using ultrafine palm oil fuel ash (POFA) and cement," Transp. Geotech., vol. 3, pp. 24-35, 2015.

[7] R. K. Sharma, "Laboratory study on stabilization of clayey soil with cement kiln dust and fiber," Geotech. Geol. Eng., vol. 35, no. 5, pp. 2291-2302, 2017.

[8] E. Mina, R. I. Kusuma, and J. Ridwan, "Stabilisasi Tanah Lempung Menggunakan Pasir Laut Dan Pengaruhnya Terhadap Nilai Kuat Tekan Bebas (Studi Kasus :Jalan Mangkualam Kecamatan Cimanggu - Banten)," J. Fondasi, vol. 6, no. 2, pp. 13-23, 2017.

[9] A. T. S. Azhar et al., "Shear Strength of Stabilized Kaolin Soil Using Liquid Polymer," IOP Conf. Ser. Mater. Sci. Eng., vol. 226, no. 1, 2017.

[10] T. R. Karatai, J. W. Kaluli, C. Kabubo, and G. Thiong'o, "Soil Stabilization Using Rice Husk Ash and Natural Lime as an Alternative to Cutting and Filling in Road Construction," J. Constr. Eng. Manag., vol. 143, no. 5, p. 04016127, 2017.

[11] H. Güllü, "Unconfined compressive strength and freeze-thaw resistance of finegrained soil stabilised with bottom ash, lime and superplasticiser," Road Mater. Pavement Des., vol. 16, no. 3, pp. 608-634, 2015.

[12] N. M. Ilieş, A. P. Cîrcu, A. C. Nagy, V. C. Ciubotaru, and Z. Kisfaludi-Bak, "Comparative Study on Soil Stabilization with Polyethylene Waste Materials and Binders," Procedia Eng., vol. 181, pp. 444-451, 2017.

[13] A. S. P, H. Beegom, J. P. Johnson, M. J, T. M. T. N, and P. S, "Potential of Egg shell powder as replacement of Lime in soil stabilization," Int. J. Adv. Eng. Res. Sci., vol. 4, no. 8, pp. 86-88, 2017.

[14] A. Ahmed and U. H. Issa, "Stability of soft clay soil stabilised with recycled gypsum in a wet environment," Soils Found., vol. 54, no. 3, pp. 405-416, 2014.

[15] G. Goel and A. S. Kalamdhad, "An investigation on use of paper mill sludge in brick manufacturing," Constr. Build. Mater., vol. 148, pp. 334-343, 2017.

[16] X. Kang, G.-C. Kang, K.-T. Chang, and L. Ge, "Chemically Stabilized Soft Clays for Road-Base Construction,” J. Mater. Civ. Eng., vol. 27, no. 7, p. 04014199, 2015.

[17] Y. J. Du, N. J. Jiang, S. Y. Liu, F. Jin, D. N. Singh, and A. J. Puppala, "Engineering properties and microstructural characteristics of cement-stabilized zinc-contaminated kaolin," Can. Geotech. J., vol. 51, no. 4, pp. 289-302, 2014.

[18] H. Christady Hardiyatmo, "Mekanika Tanah 1," p. 1, 2002.

[19] H. Canakci, A. Al-Kaki, and F. Celik, "Stabilization of Clay with Waste Soda Lime Glass Powder," Procedia Eng., vol. 161, pp. 600-605, 2016.

[20] H. Canakci, A. Aziz, and F. Celik, "Soil stabilization of clay with lignin, rice husk powder and ash," Geomech. Eng., vol. 8, no. 1, pp. 67-79, 2015. 